$(\mathrm{p}=0.040)$, but not ESR levels, as well as to the standard Ultrasound Score of 7 joints $(p \leq 0.025)(2)$. The MR-derived thermo-score could also discriminate patients in high [mean (SD) 9.2 (5.6)], moderate [mean (SD) 7.1 (3.5)] and low disease activity/remission [mean (SD) $4.2(1.8)](p=0.015)$, or aged-matched healthy subjects [mean (SD) $5.0(1.7)](p=0.002)$. Moreover, individual changes from baseline to follow-up end mirrored the corresponding DAS28 changes in $7 / 10$ patients.

Conclusions: Increased in-depth temperatures of small joints detected by MR, which are indicative of local inflammation, may serve as an additional biomarker in RA. Optimization of MR equipment and technique may result in an objective measurement of RA disease activity in clinical practice.

References:

[1] E. Zampeli, et al. Detection of subclinical synovial inflammation by microwave radiometry. PLoS ONE. 2013;(8)5:e64606.

[2] Backhaus M, et al. Evaluation of a novel 7-joint ultrasound score in daily rheumatologic practice: a pilot project. Arthritis Rheum. 2009;61(9):1194-201. Acknowledgements: None.

Disclosure of Interest: None declared

DOI: 10.1136/annrheumdis-2017-eular.3279

\section{AB0245 DISTRICT DIFFERENCES BETWEEN THE SEXES OF PREDICTIVE VALUE OF MATRIX METALLOPROTEINASE-3 AT BASELINE REGARDING CHANGES IN MODIFIED TOTAL SHARP SCORE AT 1 YEAR IN PATIENTS WITH RHEUMATOID ARTHRITIS}

K. Inui ${ }^{1}$, T. Okano ${ }^{1}$, K. Orita ${ }^{2}$, Y. Sugioka ${ }^{3}$, K. Mamoto $^{1}$, T. Koike $^{3,4}$, M. Tada ${ }^{5}$, H. Nakamura ${ }^{1}{ }^{1}$ Department of Orthopaedic Surgery, Osaka City University Graduate School of Medicine, Osaka; ${ }^{2}$ Department of Orthopaedic Surgery, Shirahama Hamayu Hospital, Shirahama; ${ }^{3}$ Center for Senile Degenerative Disorders, Osaka City University Graduate School of Medicine, Osaka; ${ }^{4}$ Search Institute for Bone and Arthritis Disease, Shirahama Foundation for Health and Welfare, Shirahama; ${ }^{5}$ Department of Orthopaedic Surgery, Department of Orthopaedic Surgery, Osaka City General Hospital, Osaka, Japan

Background: Matrix metalloproteinase (MMP)-3, also known as stromelysis-1, is expressed in inflamed synovium of patients with rheumatoid arthritis (RA). It degrades components of articular cartilage, such as proteoglycans. In Japan MMP-3 has been used as a clinical biomarker of joint destruction and its predictive value for radiographic progression has been reported.

Objectives: W aimed to confirm a relation between baseline MMP-3 and radiographic progression at 1 year and to examine the association of the MMP-3 level with ultrasonography (US) findings.

Methods: A total of 259 (213 women) consecutive patients with RA were enrolled. We collected baseline data, that included the patient's age, sex, disease duration, use of glucocorticoid or disease modifying antirheumatic drugs, Disease Activity Score-28, and modified total Sharp score (mTSS); MMP-3 and, C reactive protein levels; , rheumatoid factor or anti-citrullinated peptide antibody status,; and the power doppler score (PD) of US assessment of digits and wrists. Baseline MMP-3 level was analyzed in association with the baseline PD value and changes $(\Delta)$ in mTSS, erosion score $(\triangle \mathrm{ERN})$, joint space narrowing $(\triangle \mathrm{JSN})$ at 1 year from baseline by Pearson's correlation method. Correlations between $\triangle \mathrm{MMP}-3$ and $\triangle \mathrm{mTSS}$, or $\triangle \mathrm{PD}$ were also analyzed. Multiple regression analysis was performed, with $\triangle \mathrm{mTSS}$ as the outcome for baseline variables. Statistical analysis was performed separately by sex because the upper normal limits of MMP-3 differ between the sexes (men $\leq 121 \mathrm{ng} / \mathrm{ml}$, women $\leq 59.7 \mathrm{ng} / \mathrm{ml}$ )

Results: There was a weak correlation between the baseline MMP-3 level and baseline PD score in men. There was also moderate correlations between baseline MMP-3 level and structural damage at 1 year only in men. There was no predictive value for baseline MMP-3 level in women in terms of structural damage at 1 year. Multiple regression analysis revealed that the baseline MMP-3 level correlated independently with the $\Delta$ mTSS only in men $(p=0.0031)$, whereas in Table 1

\begin{tabular}{|c|c|c|c|c|}
\hline & Variables & Correlation coefficient & Confidence interval & $\mathrm{p}$ \\
\hline \multicolumn{5}{|l|}{ Male patients } \\
\hline \multirow[t]{4}{*}{ Baseline MMP-3 } & $\Delta \mathrm{mTSS}$ & $0.501^{\mathrm{a}}$ & {$[0.246,0.691]$} & $<0.001$ \\
\hline & $\triangle \mathrm{ERN}$ & $0.336^{\mathrm{b}}$ & {$[0.051,0.571]$} & 0.022 \\
\hline & $\triangle \mathrm{JSN}$ & $0.542^{\mathrm{a}}$ & {$[0.299,0.719]$} & $<0.0001$ \\
\hline & Baseline-PD & $0.228^{b}$ & {$[-0.074,0.492]$} & 0.136 \\
\hline \multirow[t]{4}{*}{$\triangle M M P-3$} & $\triangle \mathrm{mTSS}$ & $-0.435^{a}$ & {$[-0.644,-0.165]$} & 0.003 \\
\hline & $\triangle \mathrm{ERN}$ & $-0.325^{b}$ & {$[-0.562,-0.038]$} & 0.028 \\
\hline & $\triangle J S N$ & $-0.436^{a}$ & {$[-0.645,-0.167]$} & 0.002 \\
\hline & $\triangle P D$ & 0.134 & {$[-0.170,0.414]$} & 0.387 \\
\hline \multicolumn{5}{|l|}{ Female patients } \\
\hline \multirow[t]{4}{*}{ Baseline MMP-3 } & $\Delta \mathrm{mTSS}$ & 0.0011 & {$[-0.130,0.132]$} & 0.987 \\
\hline & $\triangle E R N$ & 0.0188 & {$[-0.113,0.150]$} & 0.780 \\
\hline & $\triangle \mathrm{JSN}$ & -0.0148 & {$[-0.146,0.117]$} & 0.826 \\
\hline & Baseline -PD & 0.0985 & {$[-0.040,0.233]$} & 0.163 \\
\hline \multirow[t]{4}{*}{$\triangle M M P-3$} & $\triangle \mathrm{mTSS}$ & -0.0344 & {$[-0.165,0.098]$} & 0.610 \\
\hline & $\triangle \mathrm{ERN}$ & -0.0485 & {$[-0.179,0.083]$} & 0.472 \\
\hline & $\triangle J S N$ & -0.0127 & {$[-0.144,0.119]$} & 0.851 \\
\hline & $\triangle \mathrm{PD}$ & 0.134 & {$[-0.0058,0.270]$} & 0.060 \\
\hline
\end{tabular}

a Moderate correlation, b Weak correlation. Statistical analysis was performed using Pearson's correlation the women the baseline PD score was correlated independently with the $\triangle \mathrm{mTSS}$ $(p=0.0003)$

Conclusions: The baseline MMP-3 level was a good predictor of deterioration of the mTSS at 1 year in male patients with RA, but not in female patients. On the other hand, the baseline PD score was a useful predictor of joint destruction in female patients with RA.

Disclosure of Interest: None declared

DOI: 10.1136/annrheumdis-2017-eular.2431

\section{AB0246 IMPACT OF TREAT TO TARGET STRATEGY WITH COMPLEMENTARY ULTRASOUND ON REAL WORLD RADIOGRAPHIC OUTCOMES IN EARLY RHEUMATOID ARTHRITIS OVER THE PAST DECADE}

K. Kobayashi ${ }^{1}$, K. Minegishi ${ }^{1}$, S. Ohno ${ }^{1}$, H. Nakajima ${ }^{2} .{ }^{1}$ Center for Rheumatic Diseases, Yokohama City University Medical Center: ${ }^{2}$ Department of Stem Cell and Immune Regulation, Yokohama City University Graduate School of Medicine, Yokohama, Kanagawa, Japan

Background: Treatment for rheumatoid arthritis (RA) has changed over the past decade. Early diagnosis and prompt agressive treatment based on treat to target strategy, as well as complementary ultrasound have been adopted and proven to improve patient clinical and radiological outcomes in clinical trials.

Objectives: The aim of this study was to compare radiographic progression of early RA patients starting their first DMARD 10 years ago vs more recently in daily clinical practice.

Methods: We reviewed the medical records of consecutive patients with symptom of 3 years duration who fulfilled the 1987 ACR classification criteria or the 2010 ACR/EULAR classification criteria in a single center retrospectively. In the first cohort (2000s), 70 patients (55.3 \pm 13.3 y.o, Female $77 \%$ ) who were diagnosed with RA during 2003-2005 were included. in the second cohort (2010s), 71 patients (54.5 $17.3 y .0$,Female90\%) who were diagnosed with RA during 2013-2015 were included. Radiographs of hands were assessed at baseline and one year after according to the van der Heijde modified Sharp score (range 0-280) without clinical information and chronological orders of radiographs in the individual patients.

Results: Mean changes in radiographic joint damage for joint space narrowing score, erosion score, total radiographic score were higher in 2000s than 2010s $(0.92 \pm 2.70$ vs $0.28 \pm 1.86 ; p=0.010,0.54 \pm 1.35$ vs $0.35 \pm 0.99 ; p=0.390,1.45 \pm 3.54$ vs $0.68 \pm 2.55 ; p=0.015$, respectively). Radiographic progression defined as total radiographic score $>0$ and $>5$ were $31.4 \%$ vs $22.5 \%$ and $8.6 \%$ vs $8.5 \%$ between 2000s and 2010s $(p=0.230$ and $p=0.970$, respectively). Methotrexate (MTX) was frequently used for initial treatment in 2010 s than 2000 s $(86 \%$ vs $55 \%$, $p<0.001$, and initial dose and maximum dose of MTX were higher in 2010s than $2000 \mathrm{~s}(9.13 \pm 2.09 \mathrm{mg} /$ week vs $4.67 \pm 1.54 \mathrm{mg} /$ week; $\mathrm{p} \leq 0.001$ and $12.04 \pm 3.73$ $\mathrm{mg} /$ week vs $8.13 \pm 1.88 \mathrm{mg} / \mathrm{week} ; \mathrm{p} \leq 0.001$, respectively). The mean duration from symptom onset to diagnosis was earlier in 2010s than 2000s $(5.75+5.04$ months vs $7.85 . \pm 6.85$ months, $p=0.001)$. CRP at baseline and 1 year after were lower in $2010 \mathrm{~s}$ than in $2000 \mathrm{~s}(2.74 \pm 1.90 \mathrm{mg} / \mathrm{dL}$ vs $3.35 \pm 3.94 \mathrm{mg} / \mathrm{dl} ; \mathrm{p}=0.001$ and $0.60 \pm 1.19 \mathrm{mg} / \mathrm{dL}$ vs $1.20 \pm 1.99 \mathrm{mg} / \mathrm{dl} ; \mathrm{p}=0.03$ respectively). There were no significant differences in sex, age, positive rate of RF and ACPA, the Sharp score at baseline, steroid use, and biological agents use between two cohorts.

Conclusions: In recent 10 years, early diagnosis with complementary ultrasound and appropriate MTX use based on treat to target strategy led to prevent joint destruction of RA patients in daily clinical practice.

Disclosure of Interest: None declared

DOI: 10.1136/annrheumdis-2017-eular.5649

\section{AB0247 EVALUATION OF RHEUMATOID ARTHRITIS CASES WITH HIGH ANTI-CCP ANTIBODY LEVEL}

K. Suzuki, M. Minami, Y. Nishio, N. Hara, S. Nakamura. Hokkaido Orthopedic Memorial Hospital, Sapporo, Japan

Background: Anti-cyclic citrullinated peptide antibodies (Anti-CCP Ab) are wellestablished serological markers that show high sensitivity and specificity in diagnosing early rheumatoid arthritis (RA). Furthermore, Anti-CCP Ab is reported to be associated with bone erosions of RA. Therefore, Anti-CCP Ab positive RA patient can be a candidate for intensive treatment.

Objectives: Upper measurement limit of Anti-CCP Ab increased recently up to 1200 units. High level of Anti-CCP Ab may be a predictor of the profound therapy for RA. To understand the importance of Anti-CCP Ab level, we evaluated RA patients with high titer Anti-CCP $A b$ in relationship to the other activity markers of $\mathrm{RA}$ and the intensity of the treatment for RA

Methods: Total of 186 RA patients with Anti-CCP Ab higher than 30 units was included in this study. Baseline markers such as CRP, MMP-3, RF and anti-CCP $\mathrm{Ab}$ were measured at the entry of the study. Relationship among these markers ware evaluated and examined using statistical significance for the single-factor ANOVA and the multiple comparisons. Among those cases 131 cases were treated conservatively with biologics and/or DMARDs and were followed up more than one year. We graded them from I to IV by the intensity of the treatment. Grade I: Biological agent. Grade II: Methotrexate (MTX) more than 12mg or combination with more than 3 DMARDS Grade III: MTX 6-11mg or combination 